\title{
PRINCÍPIOS GERENCIALISTAS NA EDUCAÇÃO PÚBLICA E A ATUAÇÃO DO PROFESSOR COORDENADOR
}

\author{
PRINCIPIOS GERENCIALISTAS EN LA EDUCACIÓN PÚBLICA Y LA ACTUACIÓN \\ DEL PROFESOR COORDINADOR
}

\author{
MANAGERIAL PRINCIPLES IN PUBLIC EDUCATION AND THE \\ PERFORMANCE OF THE TEACHER COORDINATOR
}

\author{
Vanessa LANDIM ${ }^{1}$ \\ Raquel Fontes BORGHI ${ }^{2}$
}

RESUMO: Este artigo representa parte de uma pesquisa de Mestrado que investiga a atuação do Professor Coordenador diante das avaliações em larga escala implementadas no Brasil a partir da década de 1990. Apresentaremos algumas discussões acerca do gerencialismo na educação pública brasileira e indicaremos algumas possíveis influências na atuação do Professor Coordenador. Para isso, dialogamos com Ball (2005a, 2005b), Ball e Youdell (2008), Fernandes (2004, 2008, 2009), Garcia, Adrião e Borghi (2009), Oliveira (2003), Paula (2005), Polato e Bertagna (2013). Com base nos apontamentos realizados podemos inferir que os princípios gerencialistas passaram a exercer influências sobre a educação pública e sobre a atuação do Professor Coordenador a partir da reforma do Estado que se iniciou na década de 1990 no Brasil.

PAlAVRAS-CHAVE: Gerencialismo. Performatividade. Educação pública. Professor coordenador.

RESUMEN: Este artículo representa parte de una investigación de Maestría que investiga la actuación del Profesor Coordinador ante las evaluaciones a gran escala implementadas en Brasil a partir de la década de 1990. Presentaremos algunas discusiones acerca del gerencialismo en la educación pública brasileña e indicaremos algunas posibles influencias en la actuación del Profesor Coordinador. Para ello, dialogamos con Ball (2005a, 2005b), Ball e Youdell (2008), Fernandes (2004, 2008, 2009), Garcia, Adrião e Borghi (2009), Oliveira (2003), Paula (2005), Polato e Bertagna (2013). Com base en los apuntes realizados podemos inferir que los principios gerencialistas pasaron a ejercer influencias sobre la educación pública y sobre la actuación del Profesor Coordinador a partir de la reforma del Estado que se inició en la década de 1990 en Brasil.

PALABRAS CLAVE: Gerencialismo. Performatividad. Educación pública. Profesor coordinador.

1 Universidade Estadual Paulista (UNESP), Araraquara - SP - Brasil. Mestre em educação. ORCID: http://orcid.org/0000-0002-0663-4085. E-mail: van_landim@hotmail.com

${ }^{2}$ Universidade Estadual Paulista (UNESP), Rio Claro - SP - Brasil. Professora do Departamento de Educação. ORCID: http://orcid.org/0000-0003-1486-7396. E-mail: raborghi@gmail.com 
ABSTRACT: This article represents part of a master's degree research that investigates the acting of Teacher Coordinator in the face of large-scale evaluations implemented in Brazil from the 1990s. We will present some discussions about managerialism in Brazilian public education and indicate some possible influences on the performance of the Teacher Coordinator. For this, we dialog with Ball (2005a, 2005b), Ball e Youdell (2008), Fernandes (2004, 2008, 2009), Garcia, Adrião e Borghi (2009), Oliveira (2003), Paula (2005), Polato e Bertagna(2013). Based on the notes we can infer that the managerial principles began to exert influences on public education and on the performance of the Teacher Coordinator from the State reform that began in the 1990s in Brazil.

KEYWORDS: Managerialism. Performativity. Public education. Teacher coordinator.

\section{Introdução}

Este artigo representa parte de uma pesquisa de Mestrado intitulada "O professor coordenador e sua atuação diante das avaliações em larga escala: um estudo nas redes Estadual Paulista e Municipal Rio-Clarense de Educação", na qual objetivamos compreender quais os efeitos das avaliações em larga escala, implementadas no Brasil a partir da década de 1990, sobre a atuação do Professor Coordenador, buscando evidenciar as semelhanças e diferenças entre as redes Estadual Paulista e Municipal Rio-Clarense de Educação.

Nosso enfoque neste artigo estará em apresentar e discutir o gerencialismo na educação pública brasileira e indicar algumas possíveis influências no trabalho do Professor Coordenador.

Para isso elencamos Ball (2005a, 2005b), Ball e Youdell (2008), Fernandes (2004, 2008, 2009), Garcia, Adrião e Borghi (2009), Oliveira (2003), Paula (2005), Polato e Bertagna (2013) a fim de obtermos os aportes teóricos necessários para nossa discussão.

Através dos discursos neoliberais sobre as reformas que se fazem necessárias na educação, percebemos que em todo o mundo novos sistemas educacionais estão sendo implementados nas escolas públicas levantando as bandeiras da qualidade, da competência e da eficácia. No Brasil isso não foi diferente e a partir dos anos de 1990 algumas mudanças começaram a ser implementadas nas escolas públicas a partir de reformas políticas e programas governamentais que prometiam uma solução milagrosa sobre problemas estruturais históricos da educação básica.

A crise do Estado difundida pelo pensamento neoliberal, através de críticas ao sistema burocrático e supervalorização da eficiência do sistema privado, abre espaço para os 
movimentos de reforma em que a nova administração pública passa a operar através do movimento gerencialista (PAULA, 2005, p. 27).

Buscaremos mostrar neste artigo que uma lógica de mercado vem sendo incorporada no dia a dia das escolas públicas através da atuação de seus profissionais, por meio dos discursos de modernização das práticas e da necessidade urgente de melhoria da qualidade, porém, uma qualidade pautada nos ideais da competitividade e da alta performance, que desconsidera a identidade, a coletividade e as relações, questões proeminentes ao tratarmos de formação humana.

Neste contexto, o Professor Coordenador, profissional que tem a origem de sua função atrelada a uma concepção progressista de "professor-sujeito", tem sua atuação modificada através das transformações políticas evidenciadas pelos documentos que regem a função, após a reforma do Estado ocorrida durante os governos de Fernando Color de Mello e Fernando Henrique Cardoso.

Podemos afirmar que o exercício da função em contextos progressistas, como os apresentados nas décadas de 60 e 80, assentava-se em uma concepção de professor-sujeito, capaz de constituir sua profissionalidade docente. Diferentemente, o contexto das reformas neoliberais (re)cria a função com o olhar centrado no papel do professor como objeto, a quem cabe a regulação pelas formas burocráticas de controle e de tarefas determinadas externamente. Dessa forma, a função pode ter sido necessária nas atuais reformas da Secretaria de Educação como uma alavanca para que as propostas presentes na "Escola de Cara Nova" saíssem a contento. Ao PCP coube o controle e a implantação das reformas educacionais no âmbito escolar, numa clara proximidade com os aspectos tecnicistas da educação, o que se constituiu em uma armadilha neoliberal ao processo de profissionalidade docente e de profissionalização das escolas públicas (FERNANDES, 2009, p. 7).

No estado de São Paulo, o programa "Escola de Cara Nova" correspondia a um pacote de reformas que tiveram início no ano de 1995 e tinha como objetivo reorganizar as escolas de ensino fundamental e médio (OLIVEIRA, 2003). O programa impôs mudanças como "a progressão continuada, a avaliação externa, a reorganização escolar da rede física, as salas ambientes, a implantação de projetos, a flexibilização do ensino médio e outras medidas que foram incorporadas à rotina escolar [...]". Pais foram convencidos da importância de sua participação na gestão da escola e professores foram convencidos de que deveriam se tornar “"professores reflexivos' e construtores do projeto pedagógico da escola" (FERNANDES, 2004, p. 32).

Entretanto, segundo Fernandes (2004) essas reformas se apropriaram das bandeiras progressistas para consolidar o discurso em defesa dos ideais neoliberais e diante de tantas 
melhorias propostas retoricamente, a regulamentação da função de Professor Coordenador ocorre para alavancar a efetivação das mudanças, uma vez que este seria um profissional que atuaria diretamente com as equipes docentes.

\section{Princípios gerencialistas e privatização na escola pública e da escola pública}

Diante do cenário exposto, iniciamos nossas discussões com Ball e Youdell (2008) que afirmam que algumas vezes a privatização aparece de maneira clara nas políticas que propõem soluções para os problemas da escola pública, por meio da entrada do setor privado em sua administração. Em outras, ela se dá de maneira encoberta, mas trazendo também como consequência direta a entrada efetiva do setor privado na educação.

Acerca disso, Ball e Youdell (2008) nos falam da privatização na escola pública, ou privatização endógena, aquela que promove a modificação das ideias, trazendo para a escola os métodos e práticas do setor privado, a fim de que esta se torne "tão eficiente como uma empresa"; e da privatização da escola pública, ou privatização exógena, ou seja, aquela em que o setor privado se torna o gestor e o provedor da educação.

Essas diferentes formas de privatização mudam a forma como se organiza, se gerencia e se transmite a educação, a maneira pela qual os currículos são decididos e ensinados, a maneira pela qual os resultados dos alunos são avaliados e, finalmente, a forma como são julgados os alunos, professores, escolas e comunidades locais (BALL; YOUDELL, 2008, p. 8, tradução nossa).

Essas mudanças de concepção impactam diretamente na forma como os professores são formados, em seu acesso aos cargos, nas suas atividades diárias em sala de aula, assim como na maneira em que se percebem como profissionais, ou seja, na constituição de sua identidade (BALL; YOUDELL, 2008, p. 8).

A privatização representa ainda a forma como a sociedade percebe a escola. Representa a mudança de ideais que se inspiram em uma seleção de quais habilidades são necessárias para que os alunos sejam inseridos no mercado de trabalho e não mais nos conhecimentos necessários para se formarem enquanto seres humanos críticos e reflexivos, participantes e ativos nesta sociedade.

As pressões causadas pela competição (privatização endógena) também podem ter repercussões nas formas de pedagogia aplicadas em sala de aula, com ênfase crescente no "ensinar para passar nos exames" através da memorização e da repetição. As atividades em sala de aula dos alunos são limitadas e diminuídas e o professor depende cada vez mais dos materiais pré- 
fabricados e "à prova" de qualquer intervenção pessoal do professor, de programas estatais preparados de antemão e de currículos que controlam o ritmo de aprendizagem e requerem métodos de ensino. Assim, são precisamente os professores com menos experiência que têm maior probabilidade de adotar esses sistemas obrigatórios de trabalho e, portanto, os alunos de escolas de "baixa renda" são aqueles que têm maior probabilidade de enfrentar esses regimes de ensino nas aulas (BALL; YOUDELL, 2008, p. 10 , tradução nossa).

No bojo das reformas privatistas encontram-se muitas vezes projetos experimentais financiados pelo Banco Mundial e outras agências internacionais, que encontram nos países em desenvolvimento clima e ambientes favoráveis para sua entrada e propagação (BALL; YOUDELL, 2008, p. 11).

A privatização é uma ferramenta política, que não só supõe uma renúncia por parte do Estado à sua capacidade de lidar com problemas sociais e responder às necessidades sociais, mas faz parte de um conjunto de inovações, de mudanças organizacionais e de novas relações e associações sociais, que juntas desempenham um papel importante na reconfiguração do próprio Estado. Nesse contexto, a reconfiguração da educação confere legitimidade ao conceito de educação como objeto de lucro, disponível por meio de contrato e como transação de venda (BALL; YOUDELL, 2008, p. 11, tradução nossa).

Segundo Ball e Youdell (2008) as próprias políticas educacionais são privatizadas, a partir da participação cada vez mais efetiva de ONGs e do setor privado na elaboração e efetivação dessas políticas.

Ball (2014, p. 34) argui que "novas redes e comunidades de políticas estão sendo estabelecidas por meio das quais determinados discursos e conhecimentos fluem e ganham legitimidade e credibilidade".

Para o autor, essas redes constituem mudanças no funcionamento do Estado, onde "novas fontes de autoridades" compostas por membros do próprio Estado, da economia e da sociedade civil, organizam-se de maneira interdependente, criando relações complexas que constituem, individualmente ou em grupos, políticas alternativas para gerir o "fracasso do Estado" (BALL, 2014, p. 34).

Desta forma, o desmantelamento da escola pública se dá à medida que a sociedade passa a acreditar nas denúncias sucessivas relativas ao descaso do poder público em relação aos serviços prestados pelas instituições de ensino, de forma que isso demonstra a incapacidade do governo de coordenar tais serviços e justifica a entrada do setor privado já conhecido retoricamente por sua competência gestora no que tange aos bens de consumo.

Entretanto, nos ficam os seguintes questionamentos: a educação pode ser equiparada a um bem de consumo? Podemos classificar de maneira generalizada a qualidade do ensino em 
diferentes níveis e estabelecer valores a eles de maneira que aqueles que podem pagar preços mais altos terão acesso aos melhores serviços e aqueles que podem pagar pouco terão acesso aos serviços de menor qualidade? Pensando na educação como direito (SANFELICE, 2005), é possível precificá-la e vendê-la de acordo com a lógica de "quem dá mais"?

Para Ball e Youdell (2008),

A privatização na educação pública e a privatização da educação pública podem ter um efeito muito importante na igualdade do acesso educacional, na formação e nos resultados. Sem dúvida alguma, eles podem modificar o significado de "igualdade" no campo da educação, com consequências desastrosas que podem implicar em termos de justiça social. Quando os processos de privatização estão associados à concorrência entre fornecedores e sistemas de gestão de resultados, eles podem levar a uma avaliação diferencial dos alunos e a distorções nas diretrizes de acesso. A igualdade raramente é um valor positivo em sistemas propensos ao mercado e, além disso, uma consequência da privatização é que a educação quase inevitavelmente leva a um aumento na diferenciação entre as escolas e sua estratificação, de modo que a realização de uma escolarização comum seja algo quase impossível (BALL; YOUDELL, 2008, p. 18, tradução nossa).

Esta nova gestão pública (GARCIA; ADRIÃO; BORGHI, 2009; BALL; YOUDELL, 2008; PAULA, 2005) se efetivou no Brasil a partir dos anos 1990, durante o governo de Fernando Collor de Mello (1989-1992) mas, se configurou de fato no governo de Fernando Henrique Cardoso a partir da criação do Ministério da Administração e Reforma do Estado (MARE) comandado pelo economista Luiz Carlos Bresser-Pereira, que propõe a "reforma orgânica do aparelho de estado sob a perspectiva assumida da administração gerencial" culminando na perda de espaço da democratização e do interesse público em troca de incentivos para a eficiência técnica (GARCIA; ADRIÃO; BORGHI, 2009).

Apesar da inadequação das técnicas e práticas do setor privado no setor público, justamente em função da incompatibilidade entre as lógicas gerencialistas e as de interesse público, a reforma propõe uma "simbiose entre as esferas pública e a privada" através das parcerias público-privadas, que dão origem aos "quase-mercados” (GARCIA; ADRIÃO; BORGHI, 2009, p. 547).

Os quase-mercados tem como característica o aumento da importância da figura do gestor e do conceito de nova gestão pública. Com eles ganham força os conceitos de controle de resultados, responsabilização, recursos humanos, planejamento estratégico, entre outros, que passam a fazer parte do dia a dia das escolas públicas (GARCIA; ADRIÃO; BORGHI, 2009). 
São esses novos gestores propostos pela reforma que se tornam os responsáveis pelos resultados da instituição, assim como por administrar recursos e pessoas. Esta mudança de concepções altera drasticamente a atuação do profissional da escola pública.

A ideia de nova gestão pública também tem sido o principal meio pelo qual se reestruturam a organização e a cultura dos serviços públicos a fim de introduzir e fortalecer mecanismos de mercado e formas de privatização. Dessa forma, a nova noção afeta o modo e o escopo de adoção das decisões de política social e, sistematicamente, marginaliza e subtrai todo o poder de decisão dos profissionais da educação. Por outro lado, também os submete cada vez mais frequentemente a novas formas de controle através de métodos de gestão de resultados e promove entre eles uma nova perspectiva própria através de novas formas de compromissos e prioridades, processo que poderia ser chamado de "reculturação" (BALL; YOUDELL, 2008, p. 27, tradução nossa).

Mais do que proporcionar a mudança técnica da escola pública, a reforma modifica os profissionais e suas relações, à medida que modifica toda a subjetividade que compõe a ação docente. A reforma política insere nesta ação "novos valores, novas identidades e novas formas de interação" (BALL, 2005b, p. 546).

A partir deste marco, a busca por resultados e pela qualidade da educação culminou em políticas de controle e regulação, características de um Estado gerencial. Os testes padronizados e a implantação do currículo unificado no estado de São Paulo, por exemplo, foram resultantes das políticas educacionais implementadas neste período e seguem até hoje delimitando o trabalho de gestores, professores e alunos nas escolas pertencentes à rede Estadual Paulista (POLATO; BERTAGNA, 2013, p. 13).

É dentro desse contexto "em que se defendia a autonomia da escola, a importância do desenvolvimento profissional dos professores, o professor-reflexivo e a escola como lócus da formação" que o Professor Coordenador surge como um articulador entre a Secretaria de Educação e os professores, cativando seus pares e levando-os ao cumprimento das metas estabelecidas (FERNANDES, 2004, p. 33).

A responsabilização e os mecanismos de gestão de resultados, incluindo neste caso os bônus pagos aos professores e equipes gestoras nas escolas estaduais paulistas, por exemplo, são características desse processo de entrada do setor privado na administração pública (BALL; YOUDELL, 2008, p. 28).

Nossa crítica se dá à medida que esses mecanismos promovem mudanças significativas em relação à orientação do trabalho pedagógico, o qual passa a ser pautado nos resultados e no cumprimento das metas estabelecidas (BALL; YOUDELL, 2008, p. 28). 
Para Ball e Youdell (2008), as principais mudanças que ocorrem nos sistemas de ensino geridos pela lógica de mercado dizem respeito à hierarquização por resultados:

No que diz respeito às escolas, os seguintes exemplos poderiam ser citados: governos que estabelecem padrões de referência e objetivos a serem cumpridos para as escolas e sistemas de ensino; publicação de resultados escolares sob a forma de "tabelas de classificação"; e vinculação do financiamento escolar a obrigações de desempenho (como a legislação americana chamada No Child Left Behind [em espanhol, "ausência de crianças atrasadas"], por meio da qual as escolas são obrigadas a ter seus alunos com pontuação melhor nos testes de leitura e matemática, caso contrário, eles podem perder o financiamento federal para a educação) (BALL; YOUDELL, 2008, p. 28, tradução nossa).

Para os professores as consequências são o atrelamento dos salários aos resultados, condições e contratos de trabalho definidos pelos gestores e caracteristicamente muito mais flexíveis e com menores salários, fim da relação entre titulação e vagas, além da redução de docentes com titulações justamente a fim de baratear a mão de obra e por último, adoção dos sistemas de avaliação em larga escala e responsabilização do pessoal docente, através dos resultados dessas avaliações (BALL; YOUDELL, 2008, p. 28).

Os efeitos da "mercantilização" da educação e dos profissionais docentes são sentidos à medida que as relações sociais são substituídas pela valorização do mercado. Os valores e as relações são transformados em coisas e tudo passa a ser quantificado, conforme objetivos a serem atingidos ou esperados (BALL, 2005a, p. 8).

Nesta lógica, a educação passa a ser administrada como um serviço e não mais como um direito (SANFELICE, 2005) e a escolha individual dos pais passa a ser defendida através da ótica da livre concorrência. A liberdade desta escolha é o "slogan" que encanta e garante, para os que dela fizerem uso, o pote de ouro ao fim do arco-íris.

O "valor do aluno" (BALL, 2005a) agora é determinado pelo seu desempenho e sendo assim, ele pode ser disputado ou rejeitado pelas escolas:

As exigências da concorrência, a 'informação' disponibilizada pelas Tabelas de Avaliação - Ranking das Escolas -, as pressões por parte do Estado no sentido da melhoria do desempenho, do cumprimento dos objetivos e do financiamento per capita, numa época de contenção de custos, conjugam-se no sentido de criar 'economias [locais] do valor do aluno'. Com efeito, as escolas entram em competição para recrutar os alunos mais aptos a contribuir para o 'aperfeiçoamento' e para o 'desempenho', mais fáceis e mais baratos de ensinar e mais capazes de contribuir para atrair outros como eles (BALL, 2005a, p. 14-15).

O "valor do aluno" transforma a criança em objeto, de maior ou de menor custo, o que determinará seu ingresso ou sua recusa através dos processos de seleção. Diante dessa 
conjuntura, eticamente nada impede que a classe social determine se uma criança tem maior ou menor valor para uma escola, pois quando se trata de sobrevivência no mercado "os escrúpulos relativos à dedicação e à igualdade de valor tornam-se rapidamente dispensáveis" (BALL, 2005a, p. 16).

Sob este cenário, o professor precisa optar entre ter "boas práticas" ou ter uma "boa performance". Aqueles que se arriscam a refutar a cultura normativa e optam pela autenticidade, passam a ser considerados "dinossauros morais - irrelevantes e inconvenientes", já que "a autenticidade e a performatividade entram constantemente em conflito" (BALL, 2005a, p. 22).

A reforma educativa 'convoca' um novo tipo de professor e novos tipos de saberes - um professor capaz de maximizar o desempenho, capaz de pôr de lado princípios irrelevantes ou compromissos sociais obsoletos, que encare a excelência e o aperfeiçoamento como força motriz do seu trabalho. A noção de 'fazer um bom trabalho' nesta perspectiva é reduzida a uma 'ténue' versão de profissionalismo assente na responsabilidade pelos resultados mensuráveis (BALL, 2005a, p. 22).

Com o Professor Coordenador não poderia ser diferente. É ele o protagonista da reforma da educação no Brasil. Enquanto líder, a ele cabe o convencimento das equipes de trabalho pedagógico através da mediação das relações com vistas para os resultados da escola (SÃO PAULO, 2007, s/p).

Para Ball (2005a), uma vez que as relações são substituídas por medidas de desempenho, a privatização da educação se torna mais fácil.

Em tudo isto, a própria atividade profissional passa a ser uma mercadoria. O valor substitui os valores. A reflexão moral é desnecessária, obstrutiva mesmo. O importante é a flexibilidade, em termos de competências, interesse, dedicação e moral. O novo profissional do saber não deve ser incomodado pelos escrúpulos. Predominam agora o cálculo frio e os valores exteriores. Este é o arquétipo do profissional 'pós-moderno' - definido pela superficialidade, flexibilidade, transparência e representado no seio do espetáculo, do desempenho (BALL, 2005a, p. 23).

Emerge neste cenário o que Ball (2005b) denomina "pós-profissionalismo" docente, uma mudança de identidade que acomete o professor, uma vez que suas ações passam a ser definidas por determinantes externos à sua vontade e suas crenças, sempre em busca de melhores resultados que são representados por meio de "espetáculos, em performances" (BALL, 2005b, p. 558).

Professores e demais profissionais da escola se veem diante de uma "esquizofrenia de valores" e já não sabem se devem se comprometer com o aluno e com a sua aprendizagem, arriscando-se a serem vistos como rebeldes, ou destoantes daquilo que o sistema impõe, ou se 
devem apenas se render às pressões e se adaptar, voltando seu foco para a produtividade e para a excelência de seu trabalho, não importando a que custo (BALL, 2005b, p. 551).

O profissional autêntico, aquele que se compromete com a moralidade, com a consciência política e com as emoções, aquele que se abre ao diálogo e às reflexões é substituído pelo profissional competitivo:

A eficácia prevalece sobre a ética; a ordem, sobre a ambivalência. Essa mudança na consciência e na identidade do professor apoia-se e se ramifica pela introdução, na preparação do professor, de formas novas de treinamento não intelectualizado, baseado na competência. [...] Durante o treinamento, o professor é "re-construído" para ser um técnico e não um profissional capaz de julgamento crítico e reflexão" (BALL, 2005b, p. 548).

Em geral, a performatividade na educação é expressa pela luta constante por destaque, por visibilidade. Prevalece nesta perspectiva a individualidade em busca da eficiência, do máximo desempenho, da excelência (BALL, 2005b, p. 547-548).

Como algo culturalmente construído, o gerencialismo transforma o íntimo dos profissionais da educação, pois “busca incutir a performatividade na alma do trabalhador”, que passa a se sentir responsável não apenas pelos seus próprios resultados, mas pelo de seus pares, assim como de sua instituição (BALL, 2005b, p. 545).

Nesta etapa do gerencialismo, o controle não precisa mais necessariamente ocorrer de maneira externa, já que a ideia de ranking já está impregnada nas escolas e em seus profissionais. Os bônus por desempenho podem até mesmo ser retirados, pois, como afirma Freitas (2018), trata-se de uma questão de fé alcançar bons resultados (informação verbal) ${ }^{3}$.

As relações se modificam ao passo que professores de uma mesma instituição passam a competir entre si e a julgar o trabalho daqueles que não se esforçam o suficiente - de acordo com a lógica de mercado - para garantir uma boa imagem para a organização, em termos de resultados mensuráveis:

As atividades da nova intelectualidade técnica, do gerenciamento, direcionam a performatividade para as práticas rotineiras dos professores e para as relações sociais entre professores, tornando o gerenciamento onipresente, invisível, inevitável - parte de algo que está inserido em tudo o que fazemos (BALL, 2005b, p. 554).

Cada vez mais as relações humanas e sociais são abandonadas em detrimento da lógica produtivista. A incerteza e a insegurança geram a cada dia mais doenças relativas a um ambiente

3 Informação fornecida por Luiz Carlos de Freitas, durante a palestra "Nova direita": sua política educacional e o papel da pesquisa na resistência, na FE/Unicamp, Campinas, 2018. 
instável e competitivo, já que "no âmbito de uma matriz de avaliações, comparações e incentivos relacionados com o desempenho, os indivíduos e as organizações farão o que for necessário para se distinguir ou sobreviver" (BALL, 2005b, p. 549).

Conforme dito anteriormente, podemos observar com clareza nos documentos que dispõe sobre a atuação do Professor Coordenador a inserção dos instrumentos e critérios empresariais de performatividade em suas ações. As atribuições passam a ser mais direcionadas e descrevem um profissional que se voltará especificamente para o alcance de resultados.

Diante da mudança de concepção do Professor Coordenador, este passa a ser aquele que cativa seus pares, construindo uma relação de confiança e reciprocidade, pois a conquista dessa força de trabalho garantirá que se cumpram os resultados esperados. Ele é o líder das transformações que só serão possíveis se o professor acreditar que são possíveis, acreditar na figura de liderança do Professor Coordenador.

\footnotetext{
Infelizmente, parece que as novas políticas colocam a função de professor coordenador, símbolo da democratização das relações de trabalho, em um beco sem saídas. Depois de alguns avanços, o que vemos é um retrocesso em relação ao fato do professor ser sujeito de seu próprio trabalho. Sujeito e ao mesmo tempo objeto de controle, a função adquire novas atribuições, afastando-se gradativamente dos ideais progressistas gestados nos anos 80 . Assim como as políticas neoliberais se apropriaram de outras bandeiras progressistas, tais como a autonomia e a gestão participativa, transformandoas em mecanismos de controle e regulação, talvez o mesmo esteja ocorrendo com a função de coordenação pedagógica (FERNANDES, 2008, p. 142).
}

Em suma, podemos afirmar que a função de Professor Coordenador sofreu influências diretas das políticas de privatização da educação, alterando-se radicalmente desde o seu surgimento até os dias atuais e tornando-se contraditoriamente uma função de articulação entre a Secretaria da Educação e as equipes docentes, especialmente pela proximidade com as equipes de trabalho pedagógico e pela força das relações geradas entre a categoria, tendo hoje suas práticas voltadas prioritariamente para a melhoria do desempenho das escolas nas avaliações externas.

\section{Considerações finais}

Com base nos apontamentos realizados em nossas discussões, percebemos que ao longo dos anos novas políticas voltadas prioritariamente ao controle de resultados foram sendo implementadas nas escolas públicas modificando o dia a dia dessas instituições.

Assim, podemos considerar que os princípios gerencialistas começaram a ser difundidos e passaram a exercer influências sobre a educação pública e sobre a atuação do Professor 
Coordenador a partir da reforma do Estado que se iniciou na década de 1990 no Brasil, uma vez que as concepções de educação e dos processos de ensino e aprendizagem passaram a ter um foco maior nas estratégias gerencialistas e performáticas, através das padronizações e da mensuração dos resultados presentes nas avaliações em larga escala, características de uma lógica de mercado que alterou não apenas a forma de atuação dos profissionais da escola, mas também as relações entre eles.

\section{REFERÊNCIAS}

BALL, S. J. Educação à venda. Viseu: Pretexto, 2005a.

BALL, S. J. Profissionalismo, gerencialismo e performatividade. Cadernos de Pesquisa, São Paulo, v. 35, n. 126, p. 539-564, set./dez. 2005 b.

BALL, S. J.; YOUDELL, D. La privatización encubierta en la educación pública. Instituto de Educación, Universidad de Londres, 2008.

FERNANDES, M. J. S. Problematizando o trabalho do professor coordenador pedagógico nas escolas públicas paulistas. Orientadora: Maria Helena Galvão Frem Diasda-Silva. 2004. 113 p. Dissertação (Mestrado em Educação Escolar) - Faculdade de Ciências e Letras - UNESP, Campus Araraquara, 2004. Disponível em:

http://hdl.handle.net/11449/99267. Acesso em: 5 mar. 2020.

FERNANDES, M. J. S. A coordenação pedagógica em face das reformas escolares paulistas (1996-2007). Orientador: Maria Helena Galvão Frem Dias-da-Silva. 2008. 282 p. Tese (Doutorado em Educação Escolar) - Faculdade de Ciências e Letras - UNESP, Campus Araraquara, 2008. Disponível em: http://hdl.handle.net/11449/101617. Acesso em 5 mar. 2020.

FERNANDES, M. J. S. O professor coordenador pedagógico e a fragilidade da carreira docente. Estudos em Avaliação Educacional, São Paulo, v. 20., n. 44, p. 411-424, 2009. Disponível em: http://publicacoes.fcc.org.br/ojs/index.php/eae/article/view/2037. Acesso em: 03 janeiro 2017.

GARCIA, T. O. G.; ADRIÃO, T.; BORGHI, R. A nova gestão pública e o contexto brasileiro. In: Instituições educacionais: políticas, gestão e práticas profissionais [S.l: s.n.], 2009.

OLIVEIRA, J. C. Um estudo sobre o coordenador pedagógico: sua identidade, seu trabalho e formação continuada no cotidiano escolar. Orientadora: Maria Inês G. F. Marcondes de Souza. 2009. 223 p. Dissertação (Mestrado em Educação) - Pontifícia Universidade Católica do Rio de Janeiro (PUC), Rio de Janeiro, 2009. Disponível em : https://www.maxwell.vrac.puc-rio.br/14328/14328_1.PDF. Acesso em: 5 mar. 2020.

PAULA, A. P. P. Por uma nova gestão pública: limites e potencialidades da experiência contemporânea. Rio de Janeiro: Editora FGV, 2005. 
POLATO, A.; BERTAGNA, R. H. O uso de avaliações em larga escala como forma de aferir a qualidade da educação. In: Seminário de Educação Brasileira - PNE em foco: Políticas de responsabilização, regime de colaboração e Sistema Nacional de Educação, Campinas-SP: Disponível em:

http://www.anpae.org.br/IBERO_AMERICANO_IV/GT1/GT1_Comunicacao/AmandaPolato _GT1_integral.pdf. Acesso em: 03 janeiro 2017.

SANFELICE, J. L. Da escola estatal burguesa à escola democrática e popular: considerações historiográficas. In: LOMBARDI, J. C.; SAVIANI, D.; NASCIMENTO, M. I. M. (Orgs.). A escola pública no Brasil: história e historiografia. Campinas: Autores Associados, 2005. p. 89-105.

\section{Como referenciar este artigo:}

LANDIM, Vanessa; BORGHI, Raquel. Princípios gerencialistas na educação pública e na atuação do Professor Coordenador. Revista on line de Política e Gestão Educacional, Araraquara, v. 24 n. 1, p. 24-36, jan./abr., 2020. e-ISSN: 1519-9029. DOI: https://doi.org/10.22633/rpge.v24i1.12703

Submetido em: 20/08/2019

Revisões requeridas: 30/09/2019

Aprovado em: 24/10/2019

Publicado em: 06/01/2020 